\title{
Experimental Examination of Chemical Resistance behavior of Jute Fiber Composite
}

\author{
S. Vigneshwaran, M. Uthayakumar, V. Arumugaprabu
}

\begin{abstract}
This paper investigates the chemical treated fiber reinforcement effect on the chemical resistance behavior of natural fiber reinforced polyester composite. A composite material was developed with jute fiber reinforcement in the polyester matrix. Jute fiber is reinforced in three different forms namely untreated, $\mathrm{NaOH}$ treated and Silane treated jute fibers. The chemical resistance property of the composite was investigated as per the ASTM standard. Six different chemicals were used to investigate the chemical resistance behavior of the composite. The chemical resistance property was increased with addition of treated jute fiber. All the tested composites exhibited positive results on the chemical resistance test.
\end{abstract}

Keywords : Chemical treatment, Jute fiber, Hybrid composite, chemical resistant test

\section{INTRODUCTION}

The extensive properties of polymer composites made them superior in various applications. At present in the polymer composite system more preference was given for enhancing properties through the variation in fiber reinforcement material [1]. However, polymer composites have higher strength to weight ratio when compares to metallic materials, they do not meet higher specific applications because of their limitations in certain properties like water absorption, chemical resistance [2]. This explains the inability of fiber reinforced composites in replacing the conventional materials used in specific applications. Thus by introducing modification in the fiber reinforcement, these characteristics can be enhanced considerably. Synthetic fibres are used in various superior applications but their non-degradable and recycling problems, consequently made the researches to show interest on natural fibres [3]. Compared to synthetic fibres natural fibres have many attractive characteristics like low density, easy available, bio degradable, low cost and acceptable mechanical properties [4]. However, the natural fibres have poor absorption property because of their hydrophilic property. Thus the natural fiber reinforcement more readily absorbs the chemical and waters results in failure $[5,6]$. This can be eliminated by

Revised Manuscript Received on December 05, 2019.

* Correspondence Author

S. Vigneshwaran, Faculty of Mechanical Engineering, Kalasalingam Academy of Research and Education, Srivilliputhur, India. Email: vigneshwaran.s @klu.ac.in

M. Uthayakumar*, Faculty of Mechanical Engineering, Kalasalingam Academy of Research and Education, Srivilliputhur, India. Email: m.uthayakumar@klu.ac.in

V. Arumugaprabu, Faculty of Mechanical Engineering, Kalasalingam Academy of Research and Education, Srivilliputhur, India. Email: v.arumugaprabu@klu.ac.in the proper treatment of natural fibers with chemicals. Thus in the present work jute fiber is treated chemically and composites were fabricated and investigated for the chemical resistance behaviour.

\section{MATERIALS AND METHODS}

\section{A. Material used}

For the fabrication of composite, the unsaturated polyester resin was used because of its good bonding ability with the natural fiber and also due its quick curing time. The jute fiber used were in the form of mat. The fibers were treated with the chemicals Sodium hydroxide $(\mathrm{NaOH})$ and Triethoxy (ethyl) silane. Three different composites were fabricated such as Untreated fiber composite (UC), $\mathrm{NaOH}$ treated fiber composite (NTC) and Silane treated fiber composite (STC).

\section{B. Surface modification jute fibers}

The sisal fiber mat was saturated in the alkaline solution of 5 wt. $\%$ of $\mathrm{NaOH}$ and distilled water mixture for $3 \mathrm{~h}$ at room temperature. Then the fibers were cleaned well for several times using distilled water to remove the presence of $\mathrm{NaOH}$ particles. After a thorough cleaning the fibers were tried well to avoid the presence of moisture. Similarly, silane treatment is done by the same process where the silane solution mixture was prepared with 2 wt.\% of Triethoxy (ethyl) silane).

\section{Composite fabrication and mechanical testing}

For the present investigation jute polyester hybrid composite was fabricated using compression moulding process. 3 different hybrid composites were fabricated on varying proportion of untreated jute fiber (UTF), $\mathrm{NaOH}$ treated jute fiber (NTF) and silane treated jute fiber (STF) as reinforcement. Jute fiber in the form of woven mat was used for reinforcement. In all the composite jute fiber percentage was maintained constant at $40 \%$.

\section{Chemical resistance properties}

As per ASTM D 543-87 standard, chemical resistance characteristics of the composites was found. The composites were exposed to the chemicals and their stability to the chemicals was studied in terms of weight loss. For the present work six different chemicals were used, includes two acids, two alkaline and two solvents, which are mentioned in the table 1. During the experimentation the composites were weighted initially and are immersed in the chemical solutions prepared for 24 hours at room temperature. After 24 hours of immersion the specimens were taken out, dried, pressed and the weighted. Using the weight of specimens before and after the chemical test, the

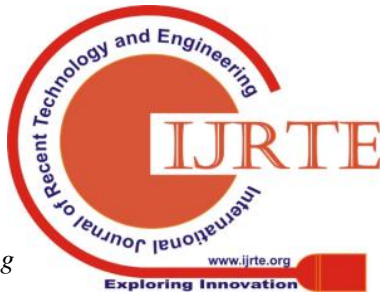


percentage of weight loss/gain was found determined by the following equation [6].

$\%$ of Weight gain/loss $\left(\mathrm{W}_{\mathrm{c}}\right)=\left(\left(\mathrm{W}_{1}-\mathrm{W}_{0}\right) / \mathrm{W}_{0}\right) \times 100$

$\mathrm{Wc}$ is weight gain/loss percentage, $\mathrm{W}_{0}$ and $\mathrm{W}_{1}$ are the weight of the specimen before and after immersion, respectively.

\section{RESULT AND DISCUSSION}

Table- I: Percentage of weight gain/loss on chemical resistance test

\begin{tabular}{|l|l|l|l|l|l|l|}
\hline Material & HCL & $\begin{array}{l}\text { Nitric } \\
\text { Acid }\end{array}$ & Toluene & Benzene & $\mathrm{NaOH}$ & $\mathrm{CaCo3}$ \\
\hline UC & 8.05 & 22.09 & 8.84 & 5.92 & 9.52 & 8.77 \\
\hline NTC & 7.02 & 11.37 & 5.71 & 7.51 & 6.43 & 7.27 \\
\hline STC & 7.08 & 11.52 & 3.82 & 2.16 & 1.36 & 10.65 \\
\hline
\end{tabular}

The stability of the composites to the chemical attack can be found through the chemical resistance test. This ensures the acceptability of these composites in the chemical orientated applications. The results of the chemical resistant test are shown in the table. The numeric value in the table is the weight loss and weight gain of the composite for 24 hours of chemical immersion. It is noted that the entire composite has gained weight after the chemical resistance test and no weight loss in noted on any composites. This ensures that these composites were stable and resistance to the chemical attack. It is noted that more weight gain was noted on the acid solution and followed by the alkaline solution. The increase in the weight is mainly because of the hydrophilicity nature of the fibre. Compared to the untreated composites treated composites showed lower weight gain, this argument the increase in chemical resistance of the treated composites. This is mainly because of the development of tight bond between the matrix and the fiber. Overall, all the developed composites showed better resistance to the chemical attack.

\section{CONCLUSION}

In the present work jute fiber reinforcement polyester composite is successfully fabricated and the chemical resistance test was done. From the experimental result outcome, the following conclusions were drawn. The composites showed good resistance on the chemical treated fiber reinforcement. This chemical resistance test clearly indicates that the silane treated fiber composites are strongly resistant to almost all chemicals and maximum weight gain was noted on nitric acid. The above observations suggest that these composites can be used in chemical erosion resistance applications.

\section{REFERENCES}

1. Dhand, Vivek, G. Mittal, K. Rhee, S. Park, and D. Hui, "A short review on basalt fiber reinforced polymer composites," Composites Part B: Engineering, vol. 73, pp. 166-180, 2015.

2. Mohammed, Layth, N. Ansari, G. Pua, M. Jawaid, and M. Saiful Islam, "A review on natural fiber reinforced polymer composite and its applications," International Journal of Polymer Science, vol. 2015, article ID 243947, 2015.
3. Saheb, D. Nabi, and P. Jog, "Natural fiber polymer composites: a review," Advances in Polymer Technology: Journal of the Polymer Processing Institute, vol. 18, pp. 351-363, 1999.

4. Tsenoglou, Christos, S. Pavlidou, and Constantine D. Papaspyrides, "Evaluation of interfacial relaxation due to water absorption in fiber-polymer composites," Composites science and technology, vol. 66, pp. 2855-2864, 2006.

5. Jawaid, A. Khalil, A. A. Bakar, and P. Noorunnisa, "Chemical resistance, void content and tensile properties of oil palm/jute fibre reinforced polymer hybrid composites." Materials \& Design, vol. 32, pp. 1014-1019, 2011

6. Uthayakumar, V. Manikandan, N. Rajini, and P. Jeyaraj, "Influence of redmud on the mechanical, damping and chemical resistance properties of banana/polyester hybrid composites." Materials \& Design, vol. 64, pp. 270-279, 2014.

\section{AUTHORS PROFILE}

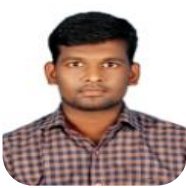

Mr. Vigneshwaran is a research scholar at Kalasalingam Academy of Research and Education, India. His area of interest includes polymer composites, composite machining and tribology.

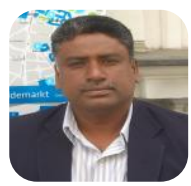

Dr. M. Uthayakumar has obtained Master of Engineering in Production Engineering from Thiagarajar College of Engineering (Autonomous), Madurai, India and Doctorate from Department of Production Engineering, National Institute of Technology, Tiruchirappalli. He has published 145 papers in the international journals and conference. Currently he is a Professor at Department of Mechanical Engineering, Kalasalingam Academy of Research and Education, Krishnankoil, Virudhunagar Dist.

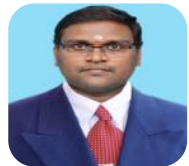

Dr. V. Arumugaprabu has completed his graduation in Mechanical Engineering and post-graduation in CAD/CAM from Arulmigu Kalasalingam College of Engineering and Mepco Schlenk Engineering College respectively. He completed his $\mathrm{PhD}$ from Kalasalingam Academy of Research and Education, India. He has 12 years of teaching experience. He has completed 1 sponsored research project from funding agencies and published more than 80 papers in peer reviewed journals and conferences. 